\title{
REVIEW
}

\section{Is community-acquired pneumonia an independent risk factor for cardiovascular disease?}

\author{
A. Singanayagam*, A. Singanayagam ${ }^{\#}$, D.H.J. Elder ${ }^{\top}$ and J.D. Chalmers ${ }^{+}$
}

ABSTRACT: Community-acquired pneumonia (CAP) is the most frequent infectious cause of death in western countries. The high mortality rate in CAP is commonly related to comorbid conditions such as cardiovascular disease.

Clinical studies in both primary and secondary care settings have identified an increase in shortand long-term risk of cardiovascular events and death from vascular events following acute respiratory infections. The mechanism remains to be fully established, but it has been suggested that the inflammatory state in patients affected by CAP acts to promote platelet activation and thrombosis, and to narrow coronary arteries through vasoconstriction. Acute infections destabilise vascular endothelium and create an imbalance between myocardial oxygen supply and demand, leading to an increased risk of cardiovascular events. Acute infections have been shown to have both systemic effects and local effects on coronary vessels. These effects are mediated through both the host response to infection and, in some cases, direct effects of bacterial infection or bacterial products.

In this review, we discuss the link between CAP and increased risk of cardiovascular events, drawing on existing evidence from clinical and mechanistic studies. Further studies into and increased awareness of this association is warranted to promote novel ways of protecting highrisk patients.

KEYWORDS: Atherosclerosis, community-acquired pneumonia, infection, myocardial infarction

ommunity-acquired pneumonia (CAP) is the leading cause of death from infectious diseases in western countries [1]. The mortality rate from CAP remains high at around $5-15 \%$ [2-6] and this figure has not changed significantly since the development of antibiotics in the 1950s [2,7]. Initial survivors of CAP have been shown to be at on-going risk of mortality in the months and years following infection [8-12].

In patients with pneumonia, more than a quarter of deaths within 30 days and nearly $50 \%$ of deaths overall are not directly related to pneumonia but are related to comorbidities $[2,13]$. The elderly population, who are those most frequently affected by $\mathrm{CAP}$, are also at high risk of mortality from cardiovascular disease [14]. Accumulating evidence points to a direct link between acute respiratory infections and an increased risk of cardiovascular events. Whether or not CAP acts as an acute trigger for cardiovascular events is important to ascertain as preventative strategies may aid in reducing mortality from this common infection.

The aim of this review is to discuss the role of CAP as a trigger for acute vascular events, drawing on evidence from experimental and clinical studies in the literature.

\section{SEARCH STRATEGY}

The current narrative review was based on a search of PubMed for articles on major MeSH terms "myocardial infarction" or "acute coronary syndrome" or "cardiovascular diseases" with "pneumonia" or "respiratory tract infections" or "sepsis" published between 1950 and December 2010. Only articles in English or English translation were reviewed. The articles were selected on the basis of originality and relevance.

\section{AFFILIATIONS}

*Dept of Respiratory Medicine, Chase Farm Hospital,

"Dept of Respiratory Medicine, St Mary's Hospital, London,

"Centre for Cardiovascular and Lung Biology, Division of Medical Sciences, University of Dundee, Dundee, and

${ }^{+}$MRC Centre for Inflammation Research, Queens Medical Research Institute, University of Edinburgh, Edinburgh, UK.

CORRESPONDENCE

A. Singanayagam

Postgraduate Centre

Chase Farm Hospital

Enfield

EN2 8JL

UK

E-mail: anika.singa@gmail.com

Received:

March 192011

Accepted after revision:

June 202011

First published online:

July 072011 


\section{ATHEROSCLEROSIS, THROMBOSIS AND PLAQUE VULNERABILITY}

Central to the pathogenesis of acute coronary syndromes and stroke are the rupture of the fibrous cap overlying a previously stable atherosclerotic plaque. The risk of plaque rupture is determined by the size and consistency of the lipid-rich core, the thickness of the fibrous cap and the extent of on-going inflammation and repair within the cap [15]. Rupture exposes the underlying lipid-rich core, which is highly pro-thrombotic. Formation of thrombus in situ leads to occlusion of the coronary (or cerebral) vessel with the subsequent clinical presentation of acute coronary syndrome or stroke [16]. The severity of disease is determined by a number of factors, including extent of thrombosis, the degree of arterial narrowing, the degree of vasoconstriction and, ultimately, the coronary perfusion pressure relative to the myocardial oxygen demand. A detailed discussion of the pathogenesis of atherosclerosis and acute coronary syndrome is beyond the scope of this review but is summarised in figure 1.

The process of plaque rupture, in situ thrombus formation and the balance of arterial perfusion versus myocardial (or cerebral) oxygen demand may be significantly affected during acute pneumonia.

\section{THE PROPOSED MECHANISM OF INCREASED CARDIOVASCULAR EVENTS FOLLOWING RESPIRATORY INFECTIONS}

A large body of evidence from clinical, in vitro and in vivo mechanistic studies provides a biologically plausible link between acute respiratory infections and atherosclerosis and thrombosis.

\section{Systemic inflammation}

Atherosclerosis is an inflammatory disorder [16]. Patients with acute coronary syndromes have evidence of systemic inflammation, with elevated pro-inflammatory cytokines and coagulation markers [22, 23]. In stable patients with atherosclerosis, raised inflammatory markers correlate with increased 10-yr cardiovascular risk [24, 25]. C-reactive protein (CRP) in particular has been identified as an independent predictor of a risk of cardiovascular events [26-31] and has been shown to correlate with the extent of coronary atherosclerosis seen on angiography [32-34]. Inflammatory cytokines (interleukin (IL)-6 and tumour necrosis factor (TNF)- $\alpha$ ) and markers of coagulation, such as fibrinogen, are elevated in patients with coronary artery disease [22, 23, 35-37].

Recent evidence has provided new information about the profound acute inflammatory response in CAP patients. CAP leads to a rapid elevation in pro-inflammatory cytokines such as CRP, IL-6, TNF- $\alpha$ and IL- 8 . These cytokines correlate to some extent with severity and decline with treatment. However, longterm follow-up studies have shown that on-going subclinical inflammation persists in CAP patients even after clinical recovery. Raised levels of IL-6 and IL-10 at hospital discharge have shown an association with an increased risk of death at $1 \mathrm{yr}$ [38]. Unfortunately, it is not yet known how long this inflammation persists after hospital discharge or how changes in cytokine levels over time in CAP correlate with vascular events.

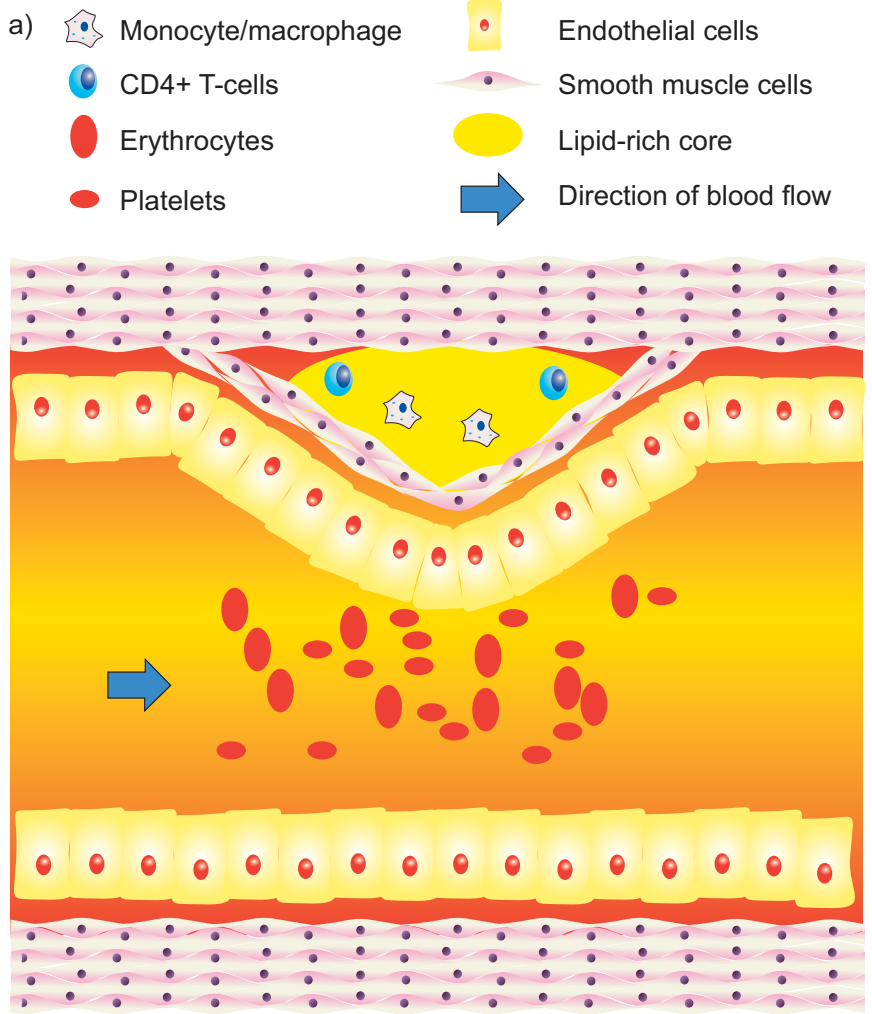

b)

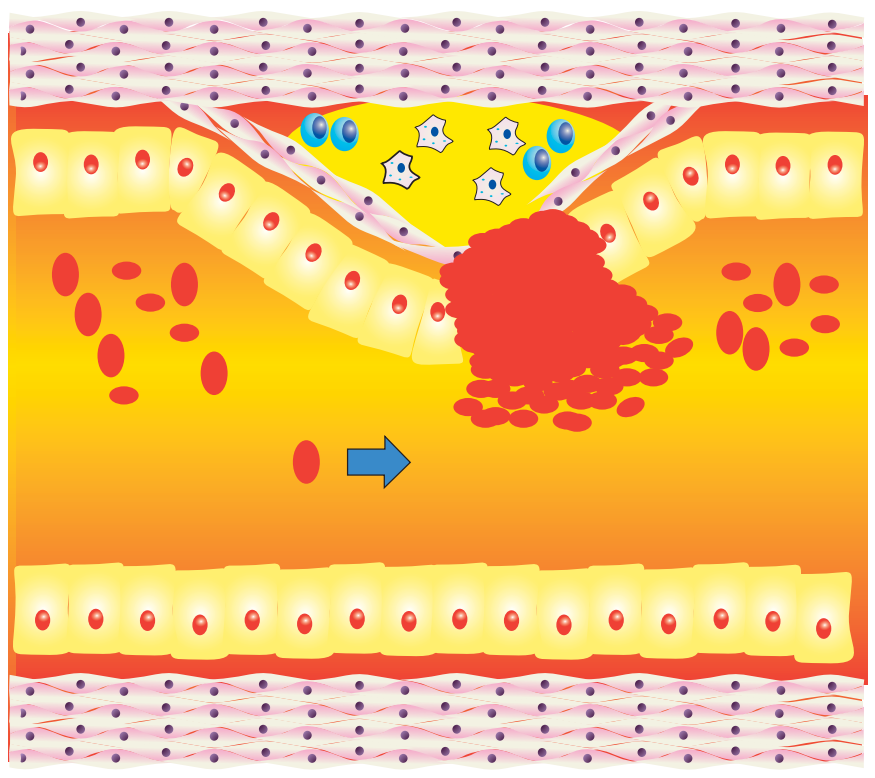

FIGURE 1. Atherosclerosis. a) Stable atherosclerotic plaque. Oxidised lipoproteins are taken up by macrophages to produce lipid-laden foam cells. Release of cytokines promotes further infiltration by macrophages and promotes smooth muscle proliferation. The fibrous cap surrounding the lipid core is dominated by vascular smooth muscle but also contains inflammatory cells. b) Ruptured atherosclerotic plaque. Rupture of the endothelial covering of the plaque exposes the highly thrombogenic lipid-rich core, leading to platelet aggregation and thrombus formation, which may occlude the coronary vessel and give rise to the clinical presentation of acute coronary syndrome [16-21]. 
Patients with CAP, therefore, have systematic inflammation that places them at risk of acute cardiovascular events not only during the acute infection, but also persisting after recovery and potentially increasing their risk over the longer term.

\section{Coronary artery inflammation}

Evidence also suggests that acute infections may trigger inflammation directly in the coronary vasculature, in addition to causing systemic inflammation. A post mortem study suggested that patients with acute infections had increased infiltration of established atherosclerotic plaques with macrophages and increased infiltration of the adventitia with macrophages, T-cells and dendritic cells [39].

\section{Platelet activation and thrombosis}

As discussed, platelet aggregation on the surface of a ruptured plaque is the initiating event in acute coronary and cerebral syndromes. Acute infections may stimulate platelet activation directly through pro-inflammatory cytokines or by bacterial products such as lipopolysaccharide (LPS) [40]. Indirect platelet activation may also result during infection from mechanical stress induced by changes in blood volume and vascular tone [41, 42].

This activation is an essential part of innate immunity, as activated platelets participate in host defence through reactive oxygen species generation, phagocytosis, cytokine release and interaction with neutrophils and monocytes [42]. This process may, however, also predispose to the initiation of thrombosis and acute ischaemic events.

CAP also induces a marked pro-thrombotic state associated with elevation of thrombotic markers such as fibrinogen, factor IX, thrombin-anti-thrombin complex and D-dimer [43-45]. Septic patients demonstrate elevated levels of tissue factor without a corresponding increase in tissue factor pathway inhibitor [46]. MiLBRANDT et al. [47] identified that significant pro-thrombotic effects and elevation of coagulation markers persisted throughout hospital stay and occurred even in patients with clinically very mild pneumonia. Data from the same group also suggest that elevation of coagulation markers is greatest in elderly patients with pneumonia, the group at greatest cardiovascular risk [48].

\section{Endothelial dysfunction}

The vascular endothelium is a dynamic autocrine and paracrine organ that regulates vascular tone and secretes vasoactive and inflammatory mediators. In atherosclerosis, there is endothelial dysfunction with impaired vascular tone and proliferation of vascular smooth muscle. Dysfunctional endothelium promotes platelet aggregation and adhesion of leukocytes [49]. In sepsis, activation of the endothelium occurs early and may be beneficial, facilitating the passage of leukocytes to infected areas [50]. However, activated endothelium releases nitric oxide, a key mediator in sepsis, resulting in vasodilation through relaxation of vascular smooth muscle. Acute infections lead to increased expression of inducible nitric oxide synthase (iNOS) with elevated nitric oxide production [51-54]. High levels of nitric oxide are toxic to the myocardium and cause systemic vasodilation [54-56], leading to increased leakiness of the systemic vascular bed and multiple organ failure [57]. The crucial role of iNOS is demonstrated by the finding that iNOSdeficient mice are relatively resistant to LPS-induced sepsis [58].
Sepsis also induces increased expression of cyclooxygenase-2 [59] leading to increased production of prostanoid mediators from the arachidonic acid pathway, including thromboxane and prostacyclin [60]. These mediators, along with endothelin-1 [61], are increased in sepsis and impair the ability of the endothelium to regulate vascular tone, prevent platelet activation and regulate inflammatory cell adhesion [54]. Furthermore, plasma von Willebrand factor levels are increased with endothelial damage, and may contribute to an overall thrombotic tendency [62].

\section{Effects of CAP on the heart}

Acute respiratory infections are associated with the damaging combination of reduced myocardial contractility, increased myocardial oxygen demand and reduced myocardial oxygen delivery.

Cytokines (IL-1, TNF- $\alpha$ and IL-6), prostanoids, endothelin-1 and nitric oxide produced in sepsis are all known to depress myocardial contractility (reviewed extensively by MERx and WEBER [54]). Decreased systolic and diastolic ventricular contractility in septic patients has been evidenced by numerous scientific and clinical studies, and results in reduced coronary perfusion pressure [54, 63, 64].

Infection also results in increased myocardial oxygen demand secondary to systemic vasodilation, tachycardia and catecholamine release. Catecholamines cause coronary vasoconstriction and endothelial dysfunction [65]. In addition, patients with respiratory infections are frequently hypoxic. Consequently, despite the increased oxygen demands described in sepsis, there may be significantly reduced myocardial oxygen delivery. Reduced myocardial oxygen delivery may lead to myocyte necrosis [66]. Cardiac troponin levels are a sensitive marker of myocyte necrosis and are frequently elevated in sepsis and are related to sepsis severity, as well as left ventricular dysfunction in sepsis [67-69].

Figure 2 summarises the proposed mechanisms of how CAP may lead to acute cardiovascular events.

\section{Direct effects of respiratory pathogens}

Experiments on apolipoprotein-deficient mice (a wellestablished mouse model of atherosclerosis) have shown that infection with influenza virus promotes inflammatory cell infiltration, smooth muscle cell proliferation and fibrin deposition in atherosclerotic plaques [70]. Unfortunately, no such study has been performed using Streptococcus pneumoniae, the most common cause of CAP. Much of the experimental work into the link between respiratory infection and atherosclerosis has been directed at Chlamydia pneumoniae. Pathological studies have identified $C$. pneumoniae in atherosclerotic plaques using numerous methods (PCR, electron microscopy and immunocytochemistry), whereas $C$. pneumoniae antigens were not detectable in normal or non-atherosclerotic segments of arterial wall $[71,72]$. Animal models have shown the atherosclerotic process to be induced and accelerated by infection with $C$. pneumoniae $[71,72]$. Whether these findings in animal models translate to the atherosclerotic process in humans remains to be seen. A number of comprehensive reviews have been published summarising the evidence for and against the link between C. pneumoniae and atherosclerosis $[73,74]$. 


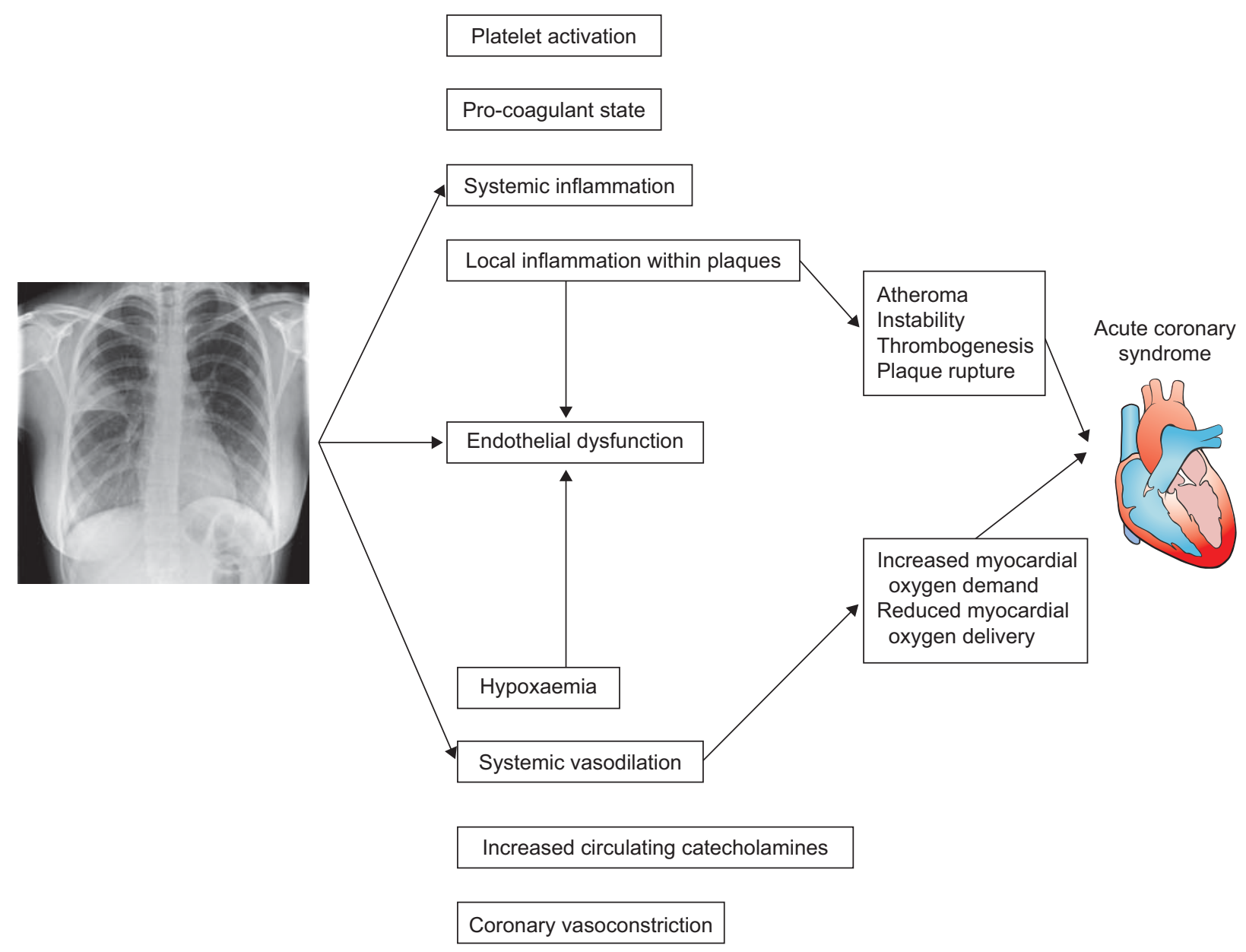

FIGURE 2. Summary of the proposed mechanisms by which community-acquired pneumonia may provoke acute coronary syndrome/acute vascular events.

\section{EVIDENCE FROM CLINICAL STUDIES Epidemiological studies}

Numerous surveillance studies have reported seasonal patterns of cardiovascular deaths, with a peak during winter months that cannot otherwise be explained by the conventionally recognised cardiovascular risk factors [75, 76]. Respiratory tract infections (RTIs) also peak in the winter, but no epidemiological studies have clearly established a link between the two disease entities.

CRAWFORD et al. [77] identified a seasonal increase in fibrinogen level and mean platelet size that corresponded to an increased incidence of acute cardiovascular events and postulated that this was linked to a seasonal pro-thrombotic state. In another study, WoODHOUSE et al. [78] suggested that the seasonal variation in fibrinogen might be induced by winter respiratory infections: fibrinogen level was strongly related to neutrophil count, CRP, self-reported cough and coryza.

\section{Population-based studies}

Large cohort studies utilising primary care databases have investigated a link between RTI and the incidence of acute vascular events in the weeks to months following infection.

Primary care research databases use computer-recorded diagnostic codes entered by general practitioners [79]. Validation studies have verified the accuracy of computer entries for acute myocardial infarction (AMI) and stroke at $>89 \%$ [80]. RTIs are entered into the database using a number of standard coding terms, including "respiratory tract infection", "bronchitis", "pneumonia" and "chesty productive cough" [81].

There have been three major primary care studies (summarised in table 1) comprising a total of 33,563 patients with first episode of AMI and 28,271 with first episode of stroke [8284]. All have documented an increased risk of AMI or stroke following RTI that persists for up to 90 days after infection. In all three studies, the increased risk was maximal shortly after infection and decreased with time. Interestingly, these studies have shown minimal or no association between urinary tract infection and AMI, suggesting the increased cardiovascular risk may be specific to respiratory infections.

These primary care-based studies are large and uniformly give similar conclusions, but there are a number of inherent limitations related to the study design. One major problem is the classification of respiratory infection within general practice databases. Diagnosing CAP in the community is challenging, as general practitioners have to rely on clinical diagnoses without chest radiographic confirmation. Previous reviews have highlighted clinical findings alone to be inadequate in diagnosing CAP [85]. Pneumonia accounts for only $5-12 \%$ of all cases of adult lower RTI treated with antibiotics by general practitioners in the community [86]. In addition, there may be some overlap between the less 


\section{TABLE 1 Evidence from primary care studies}

\begin{tabular}{|c|c|c|c|c|c|}
\hline Study & Days since RTI & OR & $\mathrm{Cl}$ & OR & $\mathrm{Cl}$ \\
\hline \multirow[t]{3}{*}{ MeIER et al. [82] } & $1-5$ & 3.6 & $2.2-5.7$ & & \\
\hline & $6-10$ & 2.3 & $1.3-4.2$ & & \\
\hline & $11-30$ & 1.2 & $0.9-1.7$ & & \\
\hline \multirow[t]{5}{*}{ SMEETH et al. [83] } & $1-3$ & 4.95 & $4.43-5.53$ & 2.57 & $2.03-3.27$ \\
\hline & $4-7$ & 3.2 & $2.84-3.6$ & 2.23 & $1.78-2.8$ \\
\hline & $8-14$ & 2.81 & $2.54-3.09$ & 1.51 & $1.23-1.86$ \\
\hline & $15-28$ & 1.95 & $1.79-2.12$ & 1.27 & $1.07-1.5$ \\
\hline & 29-91 & 1.4 & $1.33-1.48$ & 1.27 & $1.15-1.41$ \\
\hline \multirow[t]{2}{*}{ CLAyton et al. [84] } & $1-3$ & 3.75 & $1.86-7.56$ & 4.07 & $1.99-3.34$ \\
\hline & $92-365$ & 1.08 & $0.94-1.23$ & 1.08 & $0.94-1.24$ \\
\hline
\end{tabular}

RTI: respiratory tract infection; OR: odds ratio; Cl: confidence interval.

acute symptoms of coronary artery disease, left ventricular failure and acute respiratory infection. In many of these studies it is not possible to exclude the possibility of an inaccurate initial diagnosis of infection. This is also a consideration in some of the hospital-based studies described in this review.

Another major limitation of current clinical studies is that it is not possible to delineate whether the association between CAP and cardiovascular disease is because of the high burden of mutual risk factors (age, diabetes and smoking) in these patients or whether a direct link is being observed.

\section{Hospital-based and short-term studies}

Questionnaire studies of patients admitted to hospital following an AMI or ischaemic stroke have shown a frequent reporting of symptoms of respiratory infection preceding admission [87, 88]. In addition, one small study identified that positive serology for bacterial infection (including that of pathogens causing CAP, e.g. Staphylococcus aureus, S. pneumoniae, Mycoplasma pneumoniae and C. pneumoniae) was five times more likely in patients presenting with ischaemic stroke than in controls [89].

A multicentre study by LICHTMAN et al. [90] looking at noncardiac conditions in patients admitted with AMI found that $7.2 \%$ had concurrent pneumonia. A further study by the same investigators identified severe pneumonia at admission in $18.4 \%$ of patients [91]. The study by ZURRÚ et al. [92] on patients admitted with atherothrombotic ischaemic stroke noted respiratory infections in the past year to be more common, with radiologically confirmed CAP being the most prevalent type of infection (19\% in cases versus $6 \%$ in controls; OR 3.9, 95\% CI $1.9-8 ; \mathrm{p}<0.0001)$.

Overwhelmingly, therefore, in studies looking at prevalence of infection before ischaemic events, infections of the respiratory tract are consistently the most common cause. The potential overlap between respiratory and cardiac symptoms, as previously discussed, remains a concern in some of these studies.

Further hospital-based studies have looked at patients admitted with CAP for the incidence of concurrent acute cardiac events and whether clinical outcome/mortality from CAP might be attributable to AMI. These are observational studies, which typically do not utilise a control population.

MusHER et al. [93] studied 170 patients admitted with communityacquired pneumococcal pneumonia and identified concurrent AMI occurring in $7.1 \%$. 50\% of patients with concurrent myocardial infarction were bacteraemic. Mortality in patients with concurrent pneumococcal pneumonia and acute cardiac events was higher than in those with pneumonia alone (OR 3.9; $\mathrm{p}<0.008$ ).

These findings have been extended by two studies from the Community-Acquired Pneumonia Organization international database, suggesting an important role for AMI in clinical outcomes for pneumonia patients. RAMIREZ et al. [94] found AMI to be present in $5.8 \%$ of 500 consecutive patients admitted with CAP. $15 \%$ of those with severe CAP (i.e. requiring intensive care unit (ICU) admission) had concurrent AMI and an association between pneumonia severity index score and AMI was noted. Of those patients transferred to the ICU within the first $24 \mathrm{~h}$ after hospital admission, 50\% had concurrent AMI. Aliberti et al. [95] subsequently reported in the same cohort that AMI was the second most common cause of clinical failure $(28 \%$ of cases of treatment failure).

In addition, CORRALES-MEDINA et al. [96] followed patients with CAP caused by S. pneumoniae or Haemophilus influenzae for 15 days after hospital admission. In their study, they found that CAP patients were eight times more likely than controls to have a cardiac event. The risk of AMI increased to more than 40-fold when comparing the risk 1 yr before the episode of CAP with the risk during the 15-day follow-up period [97]. 


\section{Long-term studies}

A number of studies have sought to study the long-term sequelae of CAP by following patients after discharge from hospital. Overwhelmingly, these studies suggest that survivors of CAP have increased long-term mortality compared with the healthy population and that cardiovascular disease comprises a substantial proportion of long-term deaths in CAP patients. MORTENSEN et al. [2] investigated causes of mortality within 90 days of presentation with CAP. After neurological conditions and malignancy, cardiac ischaemia was identified as the third most common underlying cause of death in this cohort of patients.

Two prospective multicentre cohort studies suggest that cardiovascular events are a major cause of mortality following CAP. YENDE et al. [10] followed patients for $1 \mathrm{yr}$ and JOHNSTONE et al. [9] followed patients for an average of $5.4 \mathrm{yrs}$ after discharge. Both identified that one third of deaths following a CAP episode were due to cardiovascular causes. Recently, BRUNS et al. [11] reported an increased risk of death at 1, 5 and $7 \mathrm{yrs}$ following an episode of CAP compared with the general Dutch population. Overall, cardiovascular events contributed to $16 \%$ of deaths in this cohort. A population-based study from Finland [12] followed elderly patients for a mean of 9.2 yrs and identified a significantly increased risk of long-term mortality among CAP patients and an independent association with cardiovascular mortality (relative risk (RR) 2.4, 95\% CI 1.7-3.4; $\mathrm{p}<0.001)$.

Studies assessing cardiovascular risk in patients admitted to hospital with CAP are summarised in table 2.

\section{PREVENTATIVE MEASURES AND THE IMPACT ON THE RELATIONSHIP BETWEEN CAP AND VASCULAR EVENTS}

\section{Pneumococcal and influenza vaccination}

If respiratory infections predispose to cardiovascular events, it would be expected that prevention of respiratory infections with vaccination should also prevent vascular events. Previous studies have shown that the influenza vaccine reduces the risk of recurrent myocardial infarction, stroke and cardiac hospital admissions [98, 99], and it has been hypothesised that the pneumococcal vaccine might provide a similar protective role. To date, such studies have produced conflicting results. It is acknowledged that the currently available polysaccharide pneumococcal vaccine is probably less effective than the influenza vaccine, which may explain the incongruent results [100].

A case-control study by LAMONTAGNE et al. [101] assessing 999 patients admitted to hospital with first myocardial infarction showed that cases were less likely than controls to have been vaccinated (OR 0.53). A protective role of pneumococcal vaccination was dependent on time since vaccination, with increased protection offered if the vaccine was received $>2$ yrs previously (OR 0.33) compared with no protection if the vaccine was received $<1$ yr previously. Conversely, in a cohort study by TSENG et al. [102] involving 84,170 patients there was no significant association between pneumococcal vaccination and risk of AMI or stroke. A further case-control study from the UK of 16,012 patients with first myocardial infarction showed a significant protective benefit from influenza vaccine (OR 0.81) but not from pneumococcal vaccine [103].

A recent study from China evaluating the dual influenza/ pneumococcal vaccine has added to this debate by showing a marked reduction in mortality (hazard ratio (HR) $0.65 ; \mathrm{p}<0.001$ ), ischaemic stroke (HR 0.67; $\mathrm{p}<0.001$ ) and AMI (HR 0.52; $<<0.001$ ) in vaccinated patients compared with unvaccinated subjects [104]. In this study, both influenza vaccine and pneumococcal vaccine alone did not show a significant protective effect.

It is important to note that none of these studies were randomised controlled trials and cannot conclusively answer the question as to whether pneumococcal vaccination truly prevents acute arteriovascular events. Evidence from vaccination studies to date is summarised in table 3 .

\section{Antimicrobial therapy}

Multiple large-scale randomised placebo-controlled trials of antibiotic regimes against $C$. pneumoniae have collectively shown no major cardioprotective effect. Meta-analysis data on anti-chlamydial antibiotics and cardiovascular disease from 13 studies comprising 12,491 treated patients and 12,518

TABLE 2 Evidence from studies on patients admitted to hospital with pneumonia

\begin{tabular}{|c|c|c|c|c|c|}
\hline Study & Cases $\mathrm{n}$ & Study design & Follow-up period post CAP & Outcome & Incidence \% \\
\hline MusHeR et al. [93] & 170 & Retrospective cohort study & Duration of hospital stay & AMI & 7.1 \\
\hline RAMIREZ et al. [94] & 500 & Retrospective cohort study & Duration of hospital stay & AMl & 5.8 \\
\hline Corrales-Medina et al. [96] & 206 & $\begin{array}{l}\text { Retrospective case-control study } \\
\text { and case-crossover design }\end{array}$ & 15 days & AMI & 10.7 \\
\hline MORTENSEN et al. [2] & 208 & Prospective observational study & 90 days & Cardiovascular mortality & 13 \\
\hline BRuns et al. [11] & 356 & $\begin{array}{c}\text { Prospective observational } \\
\text { cohort study }\end{array}$ & $7 \mathrm{yrs}$ & Cardiovascular mortality & 16 \\
\hline KoIvuLA et al. [12] & 145 & Prospective observational study & $9.2 \mathrm{yrs}$ & Cardiovascular mortality & \# \\
\hline
\end{tabular}

CAP: community-acquired pneumonia; AMI: acute myocardial infarction. ${ }^{\#}$ : KoIvuLA et al. [12] did not report the overall incidence but reported a relative risk of 2.4 (95\% CI 1.7-3.4) for hospitalised CAP patients compared to matched controls without CAP. 
TABLE 3 Summary of vaccination studies

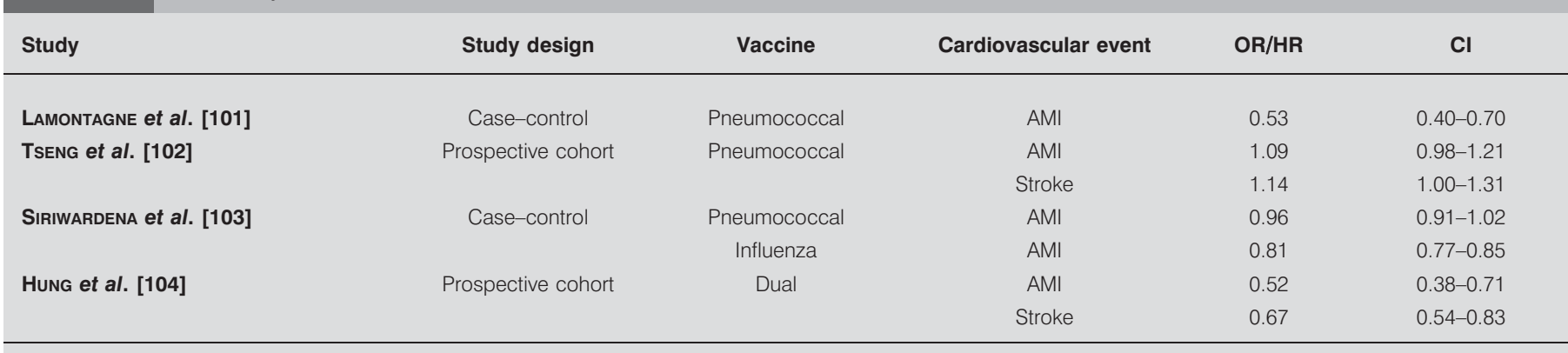

OR: odds ratio; HR: hazard ratio; Cl: confidence interval; AMI: acute myocardial infarction.

controls did not show a significant benefit (RR 0.96, 95\% CI 0.90-1.04) [105].

\section{Pharmacotherapy}

Several observational studies have shown a potential benefit of drugs used to treat cardiovascular disease on outcome for patients with CAP or sepsis. Significant reduction in shortterm mortality has been found with prior statin therapy [106] and prior angiotensin-converting enzyme inhibitor therapy in patients with CAP [106]. Statins have established immunomodulatory effects in addition to their role in preventing cardiovascular disease [99]. A recent study also suggested a possible benefit associated with anti-platelet agents [107]. A detailed discussion of the potential role of these drugs is beyond the scope of this review. These data raise the question as to whether these drugs may reduce deaths from CAP by preventing cardiovascular events.

\section{Clinical significance}

Current evidence suggests that patients with CAP are at increased short- and long-term risk of acute arteriovascular events. Cardiovascular disease is implicated in a significant proportion of deaths in CAP patients. Therapies such as anti-platelet agents, statins and angiotensin II inhibitors/angiotensin receptor blockers are established in the secondary prevention of vascular events and may become relevant treatments in the long-term management of CAP patients. The evidence so far collated (table 4) meets the Bradford Hill [108] criteria for defining causal association to some extent, but because pneumonia and cardiovascular disease share common risk factors (e.g. smoking, diabetes and age), a true causeand-effect relationship is difficult to confirm.

\section{Limitations of existing studies and future direction}

While great progress has been made in understanding the link between respiratory infections and cardiovascular events, many areas require further study. While much is known on the effects of severe sepsis on the heart and endothelium, many of the patients described in clinical studies had mild pneumonia and many did not require hospitalisation. These patients are unlikely to have had sepsis and less is known about how relatively mild infections affect the heart, vasculature and inflammatory pathways. Furthermore, there remains a lack of experimental models for research into specific CAP-causing organisms and cardiovascular disease. It may be that pneumococcal pneumonia, for example, has a more potent effect on cardiovascular disease than other organisms, as has been shown in studies of influenza virus and cardiovascular disease, compared with other viral infections.

\title{
TABLE 4 Bradford Hill [108] criteria for causality and the evidence so far
}

\author{
Criterion \\ Evidence
}

\section{Strength of association \\ Consistency of results in a variety of settings

Strong association depicted in the study by CoRRALES-MEDINA et al. [96] Patients were eight times more likely than controls to have a cardiac event 15 days after hospital admission with CAP Studies in both primary and secondary care of a variety of study designs, including case-control and cohort, have shown an increased risk of cardiovascular events following acute respiratory infection

Both pneumonia and cardiovascular disease are multifactorial and share common risk factors; therefore, this is difficult to confirm Primary care database studies showed risk of myocardial infarction decreasing with time following infection [82-84] In the study by RAmirEZ et al. [94], a positive association between pneumonia severity score and AMI was noted Experimental evidence, as highlighted in this review, supports a role for infection in cardiovascular events Laboratory, epidemiological and clinical evidence is consistent in supporting a role for infection in cardiovascular events In vitro/animal model studies specific to pneumonia are awaited Vaccination studies to date are not consistent enough to satisfy this criterion [101-104] The effect of other established cardiovascular risk factors could be considered analogous to that of pneumonia 


\section{CONCLUSION}

Current evidence suggests that CAP is associated with significant increase in short- and long-term risk of cardiovascular events and death from vascular events.

\section{STATEMENT OF INTEREST}

None declared.

\section{ACKNOWLEDGEMENTS}

The authors acknowledge the assistance of S.L. Farnworth and A. Chowdhury (University of Edinburgh, Old College, Edinburgh, UK).

\section{REFERENCES}

1 World Health Organization. The Top Ten Causes of Death. www.who.int/mediacentre/factsheets/fs310.pdf Last updated: February 2007. Date last accessed: November 30, 2010.

2 Mortensen EM, Coley CM, Singer DE, et al. Causes of death for patients with community-acquired pneumonia: results from the Pneumonia Patient Outcomes Research Team cohort study. Arch Intern Med 2002; 162: 1059-1064.

3 File TM Jr, Marrie TJ. Burden of community-acquired pneumonia in North American adults. Postgrad Med 2010; 122: 130-141.

4 Brito V, Niederman MS. Predicting mortality in the elderly with community-acquired pneumonia: should we design a new car or set a new "speed limit"? Thorax 2010; 65: 944-945.

5 Fine MJ, Smith MA, Carson CA, et al. Prognosis and outcomes of patients with community-acquired pneumonia: a meta-analysis. JAMA 1996; 275: 134-141.

6 Chalmers JD, Singanayagam A, Akram AR, et al. Severity assessment tools for predicting mortality in hospitalised patients with community-acquired pneumonia. Systematic review and meta-analysis. Thorax 2010; 65: 878-883.

7 From the Centers for Disease Control and Prevention. Pneumonia and influenza death rates - United States, 19791994. JAMA 1995; 274: 532.

8 Mortensen EM, Kapoor WN, Chang CC, et al. Assessment of mortality after long-term follow-up of patients with communityacquired pneumonia. Clin Infect Dis 2003; 37: 1617-1624.

9 Johnstone J, Eurich DT, Majumdar SR, et al. Long-term morbidity and mortality after hospitalization with community-acquired pneumonia: a population-based cohort study. Medicine (Baltimore) 2008; 87: 329-334.

10 Yende S, Angus DC, Ali IS, et al. Influence of comorbid conditions on long term mortality after pneumonia in older people. J Am Geriatr Soc 2007; 55: 518-525.

11 Bruns $\mathrm{AH}$, Oosterheert JJ, Cucciolillo MC, et al. Cause-specific long-term mortality rates in patients recovered from communityacquired pneumonia as compared with the general Dutch population. Clin Microbiol Infect 2011; 17: 763-768.

12 Koivula I, Stén M, Mäkelä PH. Prognosis after communityacquired pneumonia in the elderly: a population-based 12-year follow-up study. Arch Intern Med 1999; 159: 1550-1555.

13 Chalmers JD. ICU admission and severity assessment in community-acquired pneumonia. Crit Care 2009; 13: 156.

14 Kannel WB, Gordan T. Evaluation of cardiovascular risk in the elderly: the Framingham study. Bull NY Acad Med 1978; 54: 573-591.

15 Fernandez-Ortiz A, Badimon JJ, Falk E, et al. Characterization of the relative thrombogenicity of atherosclerotic plaque components: implications for consequences of plaque rupture. J Am Coll Cardiol 1994; 23: 1562-1569.

16 Ross R. Atherosclerosis - an inflammatory disease. N Engl J Med 1999; 340: 115-126.

17 Farmer JA, Torre-Amione G. Atherosclerosis and inflammation. Curr Atheroscler Rep 2002; 4: 92-98.
18 Hansson GK. Immune mechanisms in atherosclerosis. Arterioscler Thromb Vasc Biol 2001; 21: 1876-1890.

19 Boyle JJ. Association of coronary plaque rupture and atherosclerotic inflammation. J Pathol 1997; 181: 93-99.

20 Arbustini E, Morbini P, Bello BD, et al. From plaque biology to clinical setting. Am Heart J 1999; 138: S55-S60.

21 Shah PK. Plaque disruption and thrombosis: potential role of inflammation and infection. Cardiol Rev 2000; 8: 31-39.

22 Danesh J, Collins R, Appleby P, et al. Association of fibrinogen, C-reactive protein, albumin, or leukocyte count with coronary heart disease: meta-analyses of prospective studies. JAMA 1998; 279: $1477-1482$

23 Biasucci L, Liuzzo G, Angiolillo D, et al. Inflammation and acute coronary syndromes. Herz 2000; 25: 108-112.

24 Sakkinen P, Abbott RD, Curb JD, et al. C-reactive protein and myocardial infarction. J Clin Epidemiol 2002; 55: 445-451.

25 Park CS, Ihm SH, Yoo KD, et al. Relation between C-reactive protein, homocysteine levels, fibrinogen, and lipoprotein levels and leukocyte and platelet counts, and 10-year risk for cardiovascular disease among healthy adults in the USA. Am J Cardiol 2010; 105: 1284-1288.

26 Ridker PM. High-sensitivity C-reactive protein: potential adjunct for global risk assessment in the primary prevention of cardiovascular disease. Circulation 2001; 103: 1813-1818.

27 Ridker P. Clinical application of C-reactive protein for cardiovascular disease detection and prevention. Circulation 2003; 107: 363.

28 Pai JK, Pischon T, Ma J, et al. Inflammatory markers and the risk of coronary heart disease in men and women. N Engl J Med 2004; 351: 2599-2610.

29 Curb JD, Abbott RD, Rodriguez BL, et al. C-reactive protein and the future risk of thromboembolic stroke in healthy men. Circulation 2003; 107: 2016-2020.

30 Yeh ET. High-sensitivity $C$ reactive protein as a risk assessment tool for cardiovascular disease. Clin Cardiol 2005; 28: 408-412.

31 Koenig W, Sund M, Frohlich M, et al. C-reactive protein, a sensitive marker of inflammation, predicts future risk of coronary heart disease in initially healthy middle-aged men: results from the MONICA (Monitoring Trends and Determinants in Cardiovascular Disease) Augsburg Cohort Study, 1984 to 1992. Circulation 1999; 99: 237-242.

32 Nyandak T, Gogna A, Bansal S, et al. High sensitive C-reactive protein (hs-CRP) and its correlation with angiographic severity of coronary artery disease (CAD). J Ind Acad Clin Med 2007; 8: 217-221.

33 Katritsis D, Korovesis S, Giazitzoglou E, et al. C-reactive protein concentrations and angiographic characteristics of coronary lesions. Clin Chem 2001; 47: 882-886.

34 Tataru MC, Heinrich J, Junker R, et al. C-reactive protein and the severity of atherosclerosis in myocardial infarction patients with stable angina pectoris. Eur Heart J 2000; 21: 1000-1008.

35 Mendall MA, Patel P, Asante M, et al. Relation of serum cytokine concentrations to cardiovascular risk factors and coronary heart disease. Heart 1997; 78: 273-277.

36 Patterson CC, Smith AE, Yarnell JW, et al. The associations of interleukin-6 (IL-6) and downstream inflammatory markers with risk of cardiovascular disease: the Caerphilly Study. Atherosclerosis 2010; 209: 551-557.

37 Kelleher CC. Plasma fibrinogen and factor VII as risk factors for cardiovascular disease. Eur J Epidemiol 1992; 8: Suppl. 1, 79-82.

38 Yende S, D’Angelo G, Kellum JA, et al. Inflammatory markers at hospital discharge predict subsequent mortality after pneumonia and sepsis. Am J Respir Crit Care Med 2008; 177: 1242-1247.

39 Madjid M, Vela D, Khalili-Tabrizi H, et al. Systemic infections cause exaggerated local inflammation in atherosclerotic coronary arteries: clues to the triggering effect of acute infections on acute coronary syndromes. Tex Heart Inst J 2007; 34: 11-18. 
40 Zhang G, Han J, Welch EJ, et al. Lipopolysaccharide stimulates platelet secretion and potentiates platelet aggregation via TLR4/ MyD88 and the cGMP-dependent protein kinase pathway. J Immunol 2009; 182: 7997-8004.

41 Lassila R, Badimon JJ, Vallabhajosula S, et al. Dynamic monitoring of platelet deposition on severely damaged vessel wall in flowing blood. Effects of different stenoses on thrombus growth. Arteriosclerosis 1990; 10: 306-315.

42 Yeaman MR. Platelets in defense against bacterial pathogens. Cell Mol Life Sci 2010; 67: 525-544.

43 Puren AJ, Feldman C, Savage N, et al. Patterns of cytokine expression in community-acquired pneumonia. Chest 1995; 107: 1342-1349.

44 Antunes G, Evans SA, Lordan JL, et al. Systemic cytokine levels in community-acquired pneumonia and their association with disease severity. Eur Respir J 2002; 20: 990-995.

45 Kellum JA, Kong L, Fink MP, et al. Understanding the inflammatory cytokine response in pneumonia and sepsis: results of the Genetic and Inflammatory Markers of Sepsis (GenIMS) Study. Arch Intern Med 2007; 167: 1655-1663.

46 Gando S, Kameue T, Morimoto Y, et al. Tissue factor production not balanced by tissue factor pathway inhibitor in sepsis promotes poor prognosis. Crit Care Med 2002; 30: 1729-1934.

47 Milbrandt EB, Reade MC, Lee M, et al. Prevalence and significance of coagulation abnormalities in community-acquired pneumonia. Mol Med 2009; 15: 438-445.

48 Kale S, Yende S, Kong L, et al. The effects of age on inflammatory and coagulation-fibrinolysis response in patients hospitalised for pneumonia. PLOS One 2010; 5: e13852.

49 Vallance P, Collier J, Bhagat K. Infection, inflammation, and infarction: does acute endothelial dysfunction provide a link? Lancet 1997; 349: 1391-1392.

50 Shapiro NI, Schuetz P, Yano K, et al. The association of endothelial cell signaling, severity of illness, and organ dysfunction in sepsis. Crit Care 2010; 14: R182.

51 Kirkebøen K, Strand OA. The role of nitric oxide in sepsis - an overview. Acta Anaesthesiol Scand 1999; 43: 275-288.

52 Preiser JC, Zhang H, Vray B, et al. Time course of inducible nitric oxide synthase activity following endotoxin administration in dogs. Nitric Oxide 2001; 5: 208-211.

53 Khadour FH, Panas D, Ferdinandy P, et al. Enhanced NO and superoxide generation in dysfunctional hearts from endotoxemic rats. Am J Physiol Heart Circ Physiol 2002; 283: H1108-H1115.

54 Merx MW, Weber C. Sepsis and the heart. Circulation 2007; 116: 793-802.

55 Parratt JR. Nitric oxide in sepsis and endotoxaemia. J Antimicrob Chemother 1998; 41: Suppl. A, 31-39.

56 Kelm M, Schäfer S, Dahmann R, et al. Nitric oxide induced contractile dysfunction is related to a reduction in myocardial energy generation. Cardiovasc Res 1997; 36: 185-194.

57 Lee WL, Liles WC. Endothelial activation, dysfunction and permeability during severe infections. Curr Opin Hematol 2011; 18: 191-196.

58 Ullrich R, Scherrer-Crosbie M, Bloch KD, et al. Congenital deficiency of nitric oxide synthase 2 protects against endotoxininduced myocardial dysfunction in mice. Circulation 2000; 102 1440-1446.

59 Liu SF, Newton R, Evans TW, et al. Differential regulation of cyclo-oxygenase-I and cyclo-oxygenase- 2 gene expression by lipopolysaccharide treatment in vivo in the rat. Clin Sci (Lond) 1996; 90: 301-306.

60 Reines HD, Halushka PV, Cook JA, et al. Plasma thromboxane concentrations are raised in patients dying with septic shock. Lancet 1982; 320: 174-175.

61 Shindo $\mathrm{T}$, Kurihara $\mathrm{H}$, Kurihara $\mathrm{Y}$, et al. Upregulation of endothelin- 1 and adrenomedullin gene expression in the mouse endotoxin shock model. J Cardiovasc Pharmacol 1998; 31: S541-S544.
62 Blann AD. Plasma von Willebrand factor, thrombosis, and the endothelium: the first 30 years. Thromb Haemost 2006; 95: 49-55.

63 Maeder M, Fehr T, Rickli H, et al. Sepsis-associated myocardial dysfunction: diagnostic and prognostic impact of cardiac troponins and natriuretic peptides. Chest 2006; 129: 1349-1366.

64 Kumar A, Haery C, Parrillo JE. Myocardial dysfunction in septic shock. Crit Care Clin 2000; 16: 251-287.

65 Vita JA, Treasure CB, Yeung A, et al. Patients with evidence of coronary endothelial dysfunction as assessed by acetylcholine infusion demonstrate marked increase in sensitivity to constrictor effects of catecholamines. Circulation 1992; 85: 1390-1397.

66 Moammar MQ, Ali MI, Mahmood NA, et al. Cardiac troponin I levels and alveolar-arterial oxygen gradient in patients with community-acquired pneumonia. Heart Lung Circ 2010; 19: 90-92.

67 ver Elst KM, Spapen HD, Nguyen DN, et al. Cardiac troponins I and $\mathrm{T}$ are biological markers of left ventricular dysfunction in septic shock. Clin Chem 2000; 46: 650-657.

68 Mehta NJ, Khan IA, Gupta V, et al. Cardiac troponin I predicts myocardial dysfunction and adverse outcome in septic shock. Int J Cardiol 2004; 95: 13-17.

69 Ammann P, Fehr T, Minder EI, et al. Elevation of troponin I in sepsis and septic shock. Intensive Care Med 2001; 27: 965-969.

70 Naghavi M, Wyde P, Litovsky S, et al. Influenza infection exerts prominent inflammatory and thrombotic effects on the atherosclerotic plaques of apolipoprotein E-deficient mice. Circulation 2003; 107: 762-768.

71 Ngeh J, Anand V, Gupta S. Chlamydia pneumoniae and atherosclerosis - what we know and what we don't. Clin Microbiol Infect 2002; 8: 2-13.

72 Grayston JT. Background and current knowledge of Chlamydia pneumoniae and atherosclerosis. J Infect Dis 2000; 181: Suppl. 3, S402-S410.

73 Campbell LA, Kuo CC. Chlamydia pneumoniae - an infectious risk factor for atherosclerosis? Nat Rev Microbiol 2004; 2: 23-32.

74 Kalayoglu MV, Libby P, Byrne GI. Chlamydia pneumoniae as an emerging risk factor in cardiovascular disease. JAMA 2002; 288: 2724-2731.

75 Näyhä S. Cold and the risk of cardiovascular diseases. A review. Int J Circumpolar Health 2002; 61: 373-380.

76 Keatinge WR, Donaldson GC. Cardiovascular mortality in winter. Arctic Med Res 1995; 54: Suppl. 2, 16-18.

77 Crawford VL, McNerlan SE, Stout RW. Seasonal changes in platelets, fibrinogen and factor VII in elderly people. Age Ageing 2003; 32: 661-665.

78 Woodhouse PR, Khaw KT, Plummer M, et al. Seasonal variations of plasma fibrinogen and factor VII activity in the elderly: winter infections and death from cardiovascular disease. Lancet 1994; 343: 435-439.

79 Walley T, Mantgani A. The UK General Practice Research Database. Lancet 1997; 350: 1097-1099.

80 Jick SS, Kaye JA, Vasilakis-Scaramozza C, et al. Validity of the general practice research database. Pharmacotherapy 2003; 23: 686-689.

81 Chisholm J. The Read clinical classification. BMJ 1990; 300: 1092.

82 Meier CR, Jick SS, Derby LE, et al. Acute respiratory-tract infections and risk of first-time acute myocardial infarction. Lancet 1998; 351: 1467-1471.

83 Smeeth L, Thomas SL, Hall AJ, et al. Risk of myocardial infarction and stroke after acute infection or vaccination. N Engl J Med 2004; 351: 2611-2618.

84 Clayton TC, Thompson M, Meade TW. Recent respiratory infection and risk of cardiovascular disease: case-control study through a general practice database. Eur Heart J 2008; 29: 96-103.

85 Metlay JP, Kapoor WN, Fine MJ. Does this patient have community-acquired pneumonia? Diagnosing pneumonia by history and physical examination. JAMA 1997; 278: 1440-1445. 
86 Levy ML, Le Jeune I, Woodhead MA, et al. Primary care summary of the British Thoracic Society Guidelines for the management of community acquired pneumonia in adults: 2009 update. Primary Care Respir J 2010; 19: 21-27.

87 Spodick DH, Flessas AP, Johnson MM. Association of acute respiratory symptoms with onset of acute myocardial infarction: prospective investigation of 150 consecutive patients and matched control patients. Am J Cardiol 1984; 53: 481-482.

88 Clayton TC, Capps NE, Stephens NG, et al. Recent respiratory infection and the risk of myocardial infarction. Heart 2005; 91: 1601-1602.

89 Syrjänen J, Valtonen VV, Iivanainen M, et al. Preceding infection as an important risk factor for ischaemic brain infarction in young and middle aged patients. BMJ 1988; 296: 1156-1160.

90 Lichtman JH, Fathi A, Radford MJ, et al. Acute, severe noncardiac conditions in patients with acute myocardial infarction. Am J Med 2006; 119: 843-850.

91 Lichtman JH, Spertus JA, Reid KJ, et al. Acute noncardiac conditions and in-hospital mortality in patients with acute myocardial infarction. Circulation 2007; 116: 1925-1930.

92 Zurrú MC, Alonzo C, Brescacín L, et al. Recent respiratory infection predicts atherothrombotic stroke: case-control study in a Buenos Aires healthcare system. Stroke 2009; 40: 1986-1990.

93 Musher DM, Rueda AM, Kaka AS, et al. The association between pneumococcal pneumonia and acute cardiac events. Clin Infect Dis 2007; 45: 158-165.

94 Ramirez J, Aliberti S, Mirsaeidi M, et al. Acute myocardial infarction in hospitalized patients with community-acquired pneumonia. Clin Infect Dis 2008; 47: 182-187.

95 Aliberti S, Amir A, Peyrani P, et al. Incidence, etiology, timing, and risk factors for clinical failure in hospitalised patients with community-acquired pneumonia. Chest 2008; 134: 955-962.

96 Corrales-Medina VF, Serpa J, Rueda AM, et al. Acute bacterial pneumonia is associated with the occurrence of acute coronary syndromes. Medicine 2009; 88: 154-159.
97 Vila Córcoles A. Vaccinate your child and save its grandparents from a heart attack? Current perspectives in antipneumococcal vaccination. J Intern Med 2009; 266: 432-444.

98 Naghavi M, Barlas Z, Siadaty S, et al. Association of influenza vaccination and reduced risk of recurrent myocardial infarction. Circulation 2000; 102: 3039-3045.

99 Keller T, Weeda VB, van Dongen CJ, et al. Influenza vaccines for preventing coronary heart disease. Cochrane Database Syst Rev 2008; 3: CD005050.

100 Horwood F, Macfarlane J. Pneumococcal and influenza vaccination: current situation and future prospects. Thorax 2002; 57: Suppl. 2, ii24-ii30.

101 Lamontagne F, Garant MP, Carvalho JC, et al. Pneumococcal vaccination and risk of myocardial infarction. CMAJ 2008; 179: 773-777.

102 Tseng HF, Slezak JM, Quinn VP, et al. Pneumococcal vaccination and risk of acute myocardial infarction and stroke in men. JAMA 2010; 303: 1699-1706.

103 Siriwardena AN, Gwini SM, Coupland CA. Influenza vaccination, pneumococcal vaccination and risk of acute myocardial infarction: matched case-control study. CMAJ 2010; 182: $1617-1623$.

104 Hung IF, Leung AY, Chu DW, et al. Prevention of acute myocardial infarction and stroke among elderly persons by dual pneumococcal and influenza vaccination: a prospective cohort study. Clin Infect Dis 2010; 51: 1007-1016.

105 Song Z, Brassard P, Brophy JM. A meta-analysis of antibiotic use for the secondary prevention of cardiovascular diseases. Can J Cardiol 2008; 24: 391-395.

106 Chalmers JD, Short PM, Mandal P, et al. Statins in community acquired pneumonia: evidence from experimental and clinical studies. Respir Med 2010; 104: 1081-1091.

107 Winning J, Reichel J, Eisenhut Y, et al. Anti-platelet drugs and outcome in severe infection: clinical impact and underlying mechanisms. Platelets 2009; 20: 50-57.

108 Hill AB. The environment and disease: association or causation? Proc R Soc Med 1965; 58: 295-300. 